\title{
O REI DE ESPANHA FOI CAÇAR ELEFANTES: A CONSTRUÇÃO DISCURSIVA DO EVENTO NOS MEDIA PORTUGUESES
}

\author{
(The king of Spain hunts elephants: a discoursive \\ construction of the event in Portuguese media)
}

Rui Ramos ${ }^{1}$

(Universidade do Minho - Portugal)

\begin{abstract}
On April 13 th, the king of Spain, Juan Carlos, suffered an accident during a hunt for elephants in Botswana, which forced him to a return and urgent surgical intervention. This fact was transformed into media event by the Portuguese press, which kept it in the public sphere for several days, providing it with a certain shape, partially determined by an environmental interdiscourse which strongly condemns the killing of endangered animals and promotes its preservation. Through public speech, the media have the power to outline the perception that citizens have of the events and shape reality, and environmentalism, or the speech about the environment, is one of dominant discourses in the public sphere; so, it is academically relevant and socially useful to undertake a careful analysis of the media treatment of these facts, that is, what frame about the facts was offered to the Portuguese public opinion. To achieve this goal, this study uses the theoretical and methodological principles of discourse analysis, identifying the construction of frames and interpretive repertoires and the salient enunciative aspects identifiable in the press articles published in four daily newspapers and two weeklies in their editions of 15 to 22 April 2012.
\end{abstract}

Keywords: environmentalism, media, D. Juan Carlos

1. Doutor em Linguística, docente do Instituto de Educação e investigador do Centro de Investigação em Estudos da Criança da Universidade do Minho (Portugal), onde leciona unidades curriculares ao nível da licenciatura, do mestrado e do doutoramento. Mais informações em http://ruiramos.do.sapo.pt 


\section{RESUMO}

Em 13 de abril de 2012, o rei da Espanha, D. Juan Carlos, sofreu um acidente durante uma caçada aos elefantes, no Botswana, o que o obrigou a um regresso e a uma intervenção cirúrgica urgente. Este facto foi transformado em evento mediático pela imprensa portuguesa, que o manteve na esfera pública durante vários dias, conferindo-lhe um determinado contorno, parcialmente determinado por um interdiscurso ambiental que condena veementemente a morte de animais em vias de extinção e promove a sua preservação. Através do discurso público, os media têm o poder de moldar a percepção dos factos e configuram a realidade, e o ambientalismo, ou o discurso sobre o meio ambiente, é um dos discursos dominantes na esfera pública; por isso, é academicamente pertinente e socialmente útil desenvolver uma análise atenta ao tratamento mediático desses factos, isto é, qual desenho dos factos foi oferecido à opinião pública portuguesa. Para tal, este estudo recorre aos princípios teóricos e metodológicos da análise do discurso, identificando a construção de frames, o repertório interpretativo e os aspetos enunciativos mais salientes identificáveis em artigos de imprensa publicados em quatro jornais diários e dois semanários nas edições de 15 a 22 de abril de 2012.

Palavras-chave: ambientalismo, media, D. Juan Carlos

\section{Introdução}

O presente texto objetiva a análise linguística da cobertura mediática que os jornais portugueses fizeram do acidente que o rei de Espanha sofreu, em 13 de maio de 2012, quando participava numa caçada aos elefantes, no Botswana, e dos eventos imediatamente subsequentes - regresso urgente a Espanha, intervenção cirúrgica, divulgação das circunstâncias à opinião pública, forte reação das forças políticas e da sociedade civil, singular pedido de desculpa público do rei.

Em particular, importa averiguar qual o frame (Fillmore, 1975; Vilela, 1994) em que este evento é inserido pelas entidades mediáticas, qual o sentido que é construído no espaço público pelos jornais nacionais para estes factos brutos. A circunstância de D. Juan Carlos, presidente honorário da WWF - World Wide Fund for Nature em 
Espanha, participar numa caçada a uma espécie protegida e em vias de extinção e de esse facto ser apropriado pelo discurso público, que encontra nos jornais e restante media espaço de constituição e agonia, parece incorporar o potencial para ser discutida na sua essência e criar reflexão no espaço público sobre o equilíbrio natural, a preservação das espécies e a relação homem / ambiente, a partir dos discursos públicos produzidos.

Esta escolha e a respetiva justificação inscrevem-se numa linha teórica já defendida por outros linguistas, nomeadamente Jung (2001). Este considera que a adaptação linguística às rápidas alterações dos contextos sociais e ambientais está só muito lateralmente ligada à experiência individual primária e, por isso, o fator decisivo de seleção dos discursos ambientais relevantes para a análise académica deve ter em consideração as experiências "em segunda mão" geradas e mediadas pelos media, e é nesse campo que a comunidade científica deve desenvolver os seus esforços de explicação dos fenómenos que associam linguagem e ambiente e, eventualmente, contribuir para a solução dos problemas ambientais, como é seu propósito confesso. Afirma o autor que a consciência social e a ecológica são formadas conjuntamente através do discurso público e a linguagem não desempenha um papel de mero instrumento externo para a transmissão de conteúdos de consciência, mas tem uma influência determinante na formação do pensamento e no que é transmitido.

\section{Quadro teórico}

O quadro teórico no qual este estudo se inscreve assume que a língua e os discursos configuram a realidade (Searle, 1998) e colaboram na categorização das coisas e seus estados, visto que é pelo discurso produzido que o sujeito falante constrói o mundo, um mundo necessariamente modelado pela sua perceção e pelos valores que adota como seus. Ou seja, o discurso não apresenta asseticamente os factos brutos, na sua absoluta completude, mas opera uma seleção e uma mediação entre as coisas e seus estados 
e o homem, sendo toda a enunciação uma forma de ordenação e conceptualização do mundo.

Quer consideremos, como Benveniste (1974), que o ato de enunciação corresponde a uma apropriação individual do sistema da língua pelo sujeito falante e, portanto, à manifestação primordial de subjetividade, quer consideremos, tal como Ducrot, que a enunciação é um acontecimento inscrito no devir histórico que faz ouvir vozes anteriores à construção de cada enunciado, a apropriação do sistema formal da enunciação define necessariamente as coordenadas de cada enunciador, o seu ego, hic et nunc e ainda o seu sic, ou seja, a forma particular e individual (depois partilhada, discutida, negociada) de construir a visão do mundo que assume como sua. Esta visão do mundo é modelada pela cultura do enunciador, pelos seus valores, crenças e memória histórica, mas também pelos seus objetivos estratégicos específicos, associados a cada circunstância concreta de uso da palavra.

As considerações elaboradas convergem com a noção de "construtivismo linguístico" (Halliday, 2001), que evoca a capacidade da linguagem para balizar a consciência de cada indivíduo e fornecerlhe a teoria que subjaz à sua interpretação e manipulação das coisas e seus estados. Segundo o autor, a linguagem não reflete passivamente a realidade, mas cria-a ativamente. Ou seja: a língua, atualizada nos discursos que cada enunciação produz, é concebida como um sistema modelizante do mundo, como uma "forma de vida" (Fonseca, 1998), e os discursos são entendidos como práticas e produtos de uma ordenação intelectiva, de uma seleção, recriação, organização e avaliação do mundo ${ }^{2}$.

Assinale-se ainda que o discurso ambiental, aqui entendido como aquele em que a relação entre o homem e o seu ambiente é questionada, faz parte do que Jung (2001) designa como discursos públicos dominantes, ou seja, os discursos que se constroem na esfera pública relevante, que são objeto de polémica discursiva e que

2. De acordo com Dryzek (1997), partilhar um discurso significa partilhar suposições, julgamentos e disputas que fornecem os termos básicos para a análise, o debate, os acordos e os desacordos". 
adquirem a capacidade de influenciar substancialmente o pensamento e a ação da generalidade dos cidadãos.

No que respeita especificamente aos textos da imprensa, há que assinalar, como Charaudeau (1997), que os media não transmitem o que se passa na realidade social, mas impõem o que constroem com o material circulante no espaço público. Esta constatação é particularmente relevante se considerarmos que, nas modernas sociedades ocidentais, são os media que nos trazem quotidianamente o mundo às mãos e aos olhos e que nos oferecem o sentido para o que acontece, através da sua seleção, avaliação e mediação (ou modalização) $)^{3}$.

Tal mediação adquire materialidade nos diferentes modos de construção dos géneros textuais da imprensa. A propósito da forma destes textos, e nomeadamente do modo como são apresentados ao nível enunciativo, Moirand (1999) distingue dois grandes grupos: os textos de enunciação objetivizada e os textos de enunciação subjetivizada. Os primeiros correspondem àqueles em que o enunciador se oculta sob uma aparente neutralidade e simula referir ou descrever os factos fora de qualquer tipo de avaliação, sem fazer intervir no relato o seu ponto de vista, sem marcas formais de subjetividade. Os segundos são aqueles em que o enunciador se assume explicitamente como avaliador dos estados de coisas, dá a ver as suas escolhas e a seleção que opera entre os factos brutos.

\section{Corpus e metodologia}

O corpus de análise integra todas as peças jornalísticas publicadas sobre o acidente do rei de Espanha e suas consequências imediatas, ao longo de uma semana, entre 15 e 22 de abril, em seis periódicos de difusão nacional em Portugal: os diários de referência Público e Diário de Notícias (DN), os diários populares Jornal de Notícias (JN) e Correio da Manhã (CM) e os semanários Expresso e Visão (este em formato de

3. Cf.: Bronckart, 2009. 
revista). No total, foram identificadas 58 peças jornalísticas, número que inclui chamadas de primeira página, notícias, entrevistas, breves, caixas de textos-satélite ${ }^{4}$, crónicas humorísticas, uma carta ao diretor e artigos de opinião.

A análise, como se verá na seção seguinte, traça um quadro geral do tratamento feito, apontando os frames relevantes, sobretudo a partir do repertório interpretativo (Potter \& Wetherell, 1987; McKenzie, 2005) identificável, e se detém com maior atenção sobre os artigos que evocam e discutem a questão ambiental ${ }^{5}$, identificando a variação de construção textual e de posicionamento enunciativo de textos de enunciação objetivizada e textos de enunciação subjetivizada. Estes últimos serão objeto de análise mais demorada, em virtude de suscitarem de forma mais visível a reflexão e o debate na esfera pública.

\section{Evidências do corpus e discussão}

Os dois jornais populares, JN e CM, produzem o mesmo número de artigos em torno deste evento: sete. No caso do JN, só dois destes referem a questão ambiental; no caso do CM, são três os artigos que o fazem. Quanto aos diários de referência, o Público publicou um total de 10 peças jornalísticas, quatro delas evocando a mesma questão (duas são artigos humorísticos do encarte Inimigo Público); o DN, entre 28 peças jornalísticas, apresenta 10 que promovem a reflexão em torno do topos ambiental. Finalmente, os semanários Expresso e Visão apresentam três artigos cada sobre este caso, cada título oferecendo à leitura dois textos que integram o frame ambiental ${ }^{6}$. Em termos de intensidade de cobertura, o DN sobressai claramente. Não só apresenta o maior número de artigos

4. Para a noção de texto-satélite (e também de texto diretor), ver Ramos, 2007, 2009, 2009a.

5. Esta designação servirá para referir, de forma sintética, ao questionamento sobre o ato de matar elefantes, como desporto, também chamado "caça de troféu", no quadro da relação homem / ambiente, e nomeadamente no caso concreto aqui abordado, focalizado em torno de Juan Carlos e sua caçada.

6. $C f:$ :Quadros 1 a 6 . 
(28, praticamente metade do total), como evoca o assunto por três vezes na primeira página das suas edições.

\subsection{Uma visão panorâmica do corpus}

Uma visão panorâmica do corpus permite identificar quatro frames sobre os quais os textos se constroem. Um primeiro frame será o da vida política, em torno das relações entre o rei e o governo espanhol, suscitado pelo facto de este se ter ausentado sem dar disso conhecimento àquele, numa viagem que considerou ser de índole privada. Só a ocorrência do acidente e suas consequências transferiu aquilo que era do domínio privado para o domínio público. Algumas forças políticas viram neste ato um motivo para evocarem a questão do regime (monárquico versus republicano) ou para reclamarem a resignação do rei em favor do príncipe.

Um segundo frame remete para a vida privada, para as vivências e ocorrências no seio da família real. São evocados casos recentes, por vezes referidos como "escândalos", já conhecidos publicamente, do julgamento por corrupção de Iñaki Urdangarín, genro do rei, e do acidente com Fróilan, o neto mais velho do rei, de 13 anos que, manejando uma arma de fogo (apesar de isso só ser permitido após os 14 anos de idade), deu um tiro no próprio pé; e é explorada a vida conjugal dos reis, aparentemente só existente em cerimónias oficiais públicas, assim como os casos amorosos de Juan Carlos, nomeadamente a sua relação com Corinna zu Sayn-Wittgenstein, apresentada como amante oficial. Dois jornais, o JN e o DN, entrevistam a jornalista espanhola Pilar Eyre, autora de uma biografia da rainha Sofia de Espanha, e dão visibilidade a esta questão privada e familiar, até há pouco tempo não discutida no país.

Um terceiro frame evoca a economia. Este frame está presente de forma muito relevante em todos os jornais e em praticamente todos os textos, de forma direta ou indireta, sublinhando insistentemente a incoerência existente entre a crise económica que afeta profundamente a sociedade espanhola e o que parece ser um gasto faustoso do rei, numa atividade lúdica, o que pode ser interpretado quase como um 
insulto aos seus súbditos. Esta dicotomia entre privação e fausto, entre crise e esbanjamento, é explorada em grande número de artigos e faz títulos como "Caçada do rei em tempos de crise abre debate sobre família real" (Público, 14/4/2012, pp. 1). Em alguns casos, após uma primeira notícia mais limitada em informações, os jornais fazem o relato das explicações da casa real, segundo a qual o rei não terá gasto dinheiro dos contribuintes nesta atividade, já que teria estado presente na caçada como convidado.

Finalmente, há que identificar o frame ambiental, manifestando a estranheza pela atividade de caçar uma espécie protegida, um ato completamente afastado das expectativas de normalidade para a grande maioria dos portugueses (e, provavelmente, também dos espanhóis), ato tanto mais inesperado quanto o rei é o presidente honorário do WWF em Espanha, uma associação de defesa ambiental. A aparente contradição entre presidir a uma associação que defende a vida selvagem e a participação em caçadas a animais selvagens vem acumular o julgamento negativo sobre o ethos de Juan Carlos, sendo o caráter uma dimensão fundamental do perfil de um monarca.

Feita a panorâmica geral dos campos conceptuais que assistem ao desenvolvimento temático e organizativo dos artigos em análise, cabe particularizar a atenção em alguns textos mais relevantes.

\subsubsection{O Jornal de Notícias (JN)}

No JN, só um artigo pode ser classificado entre os textos de enunciação subjetivizada: trata-se de uma crónica. Esta tece uma crítica severa e sarcástica ao rei de Espanha, desenvolvendo-se sobre o topos do "divertimento" real:

(1) Como os reis se divertem

Juan Carlos Alfonso Victor María de Borbón y Borbón-Duas Sicilias, Rei de Espanha (e ainda, a crer nos seus títulos, de "reinos" como o de Jerusalém, de Nápoles, da Sicília, da Sardenha e das Índias Orientais e Ocidentais...), decidiu, cansado dos entediantes afazeres da realeza, divertir-se. 
E que melhor maneira de se divertir do que pegar numa carabina e matar elefantes? (JN, 16/4/2012, pp. 48) ${ }^{7}$

Este parágrafo inicial manifesta suficientemente a posição em que o enunciador se coloca face ao objeto do seu texto, mostrando desde o início o seu caráter polémico ${ }^{8}$. Entenda-se o adjetivo 'polémico', neste contexto, como caraterizando os textos / discursos que assumem como objetivo pragmático dominante a desqualificação do alvo. De acordo com Kerbrat-Orecchioni (s/d), o discurso polémico é um discurso desqualificante, que elege e ataca um alvo específico, colocando ao serviço desse objetivo pragmático (desacreditar o adversário e o discurso respetivo) todo o arsenal dos seus recursos retóricos e argumentativos.

De facto, surge como ridículo aos olhos do leitor comum o exageradamente extenso nome do rei, com apelidos repetidos (em parte, porque absolutamente desnecessário para identificar o indivíduo em causa), assim como o elenco dos seus pretensos domínios, alguns deles inexistentes; mas afigura-se não menos ridicularizante a afirmação de que este se teria entediado com as suas tarefas, numa evocação sintética de um saber comum partilhado entre enunciador e enunciatários, com reminiscências de conto infantil, numa configuração ultrassimplificada e ingénua das funções do rei. A nota intensifica-se com a solução que o texto apresenta como aquela que teria sido encontrada pelo rei para combater o seu tédio: pegar numa carabina e matar elefantes. Acresce que esta é uma atitude dada como consciente e deliberada do protagonista: ele "decidiu" - é, portanto, apresentado como agente, assumindo plenamente a responsabilidade do seu ato.

Ao mesmo tempo, pode verificar-se que é estabelecida uma relação causal explícita entre as duas realidades: o rei mata elefantes porque se sente entediado. Este é um estado de coisas estranho aos cidadãos comuns, alheio às suas vivências, contrário às expectativas de normalidade e frontalmente oposto ao discurso público dominante.

7. Nem todos os artigos usam a norma ortográfica prevista no mais recente Acordo Ortográfico; por isso, a norma foi atualizada em todos os casos.

8. Cf. Ramos, 1998. 
Assim, quem adota as atitudes descritas, quem se apresenta com tão intensa frivolidade, é necessariamente afetado por algum tipo de exclusão da norma, ou da normalidade. O contraste é exponencialmente aumentado pelo facto de as responsabilidades do sujeito serem da mais elevada importância e, portanto, com o contraste, aumenta a intensidade da condenação.

Um outro segmento é passível de referência:

(2) O "Público online" divulgou uma fotografia do viril monarca, de falo significante na mão, posando orgulhosamente diante do cadáver prostrado de um elefante (JN, 16/4/2012, pp. 48)

Esta afirmação refere-se a uma fotografia amplamente divulgada, presente (à data do conhecimento público da caçada de Juan Carlos ${ }^{9}$ ) na página da internet da empresa organizadora do safari e reproduzida oito vezes nos quatro diários ${ }^{10}$. Trata-se da imagem apresentada a seguir.

O autor do artigo identifica a arma que Juan Carlos empunha como um "falo significante"; admitindo coerência textual, o leitor reconhecerá que, inscrevendo-se no mesmo topos, a qualificação do rei como "viril monarca" se justifica por tal manifestação fálica, a virilidade sendo o significado associado ao "significante falo". Esta construção colabora na desqualificação do indivíduo, visto que tal virilidade resultaria de um apetrecho externo, só necessário se essa caraterística íntima estiver debilitada, e que o rei exibiria publicamente. Evoca implicitamente a voz comum que associa as manifestações externas de virilidade, força, autoridade ou valentia masculinas a estratégias de ocultação e sublimação de fragilidades internas. Assim, o adjetivo "viril" corresponderia a uma utilização irónica, mostrando

9. Segundo o DN, na sua edição de $15 / 4 / 2012$, a fotografia data de 2006 e terá sido retirada da página da empresa de safaris, em www.rannsafaris.com, após a polémica pública.

10. Presente em: Público 16/4/2012, pp. 37; DN 15/4/2012, pp. 24; 16/4/2012, pp. 24; 18/4/2012, pp. 26; 20/4/2012, pp. 28; JN 15/4/2012, pp. 30; CM 15/4/2012, pp. 31; 17/4/2012, pp. 28. 
uma avaliação do enunciador oposta ao do sentido denotativo do termo.

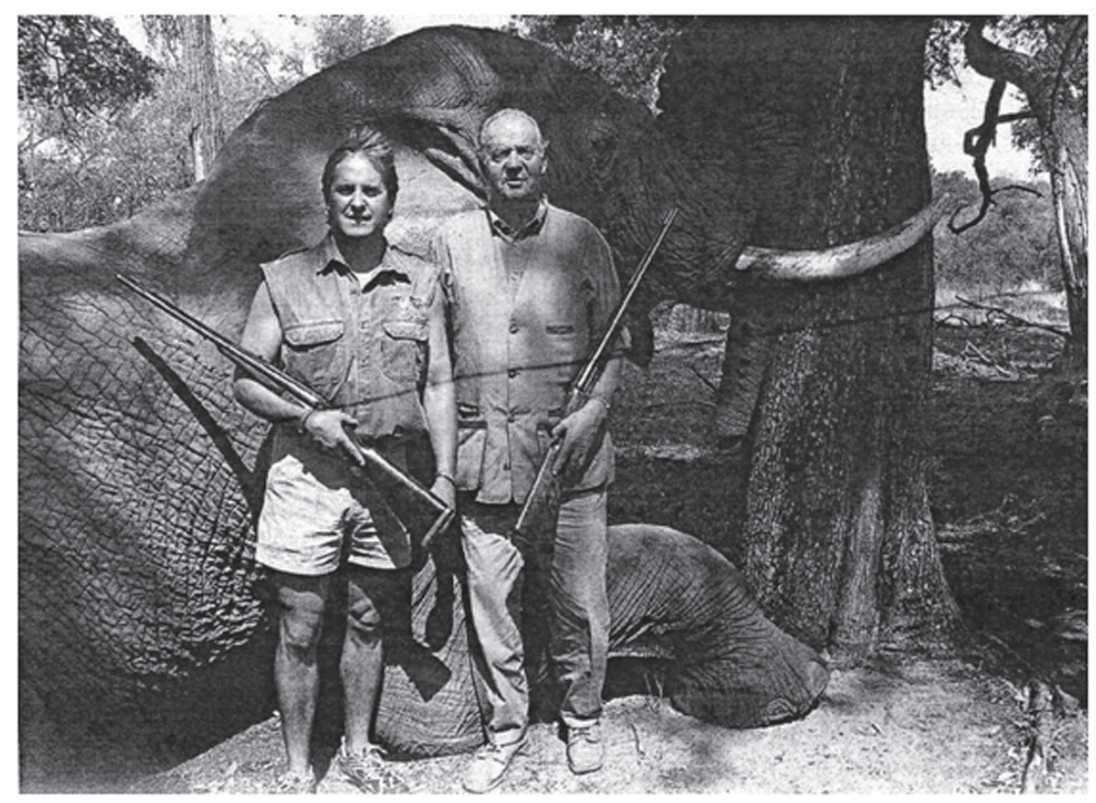

Fonte: www.rannsafaris.com

Como se pode observar, trata-se de uma desqualificação forte do rei, não só como líder, mas também como homem, apresentado ironicamente como incapaz, no que poderá ser visto como o derradeiro insulto que pode fazer-se a um homem cujas atitudes e práticas se pautam por valores tradicionais, como os que estão associados a um rei que "vai à caça". Na fotografia, Juan Carlos surge, de facto, na frente do cadáver de um belo e grande elefante africano, ajoelhado, a cabeça forçada a manter-se em posição vertical pelo apoio fornecido por uma involuntária árvore, a tromba em posição não natural. A imagem poderá ser chocante para os mais radicais defensores dos animais, que verão nela a suprema humilhação do animal abatido e exposto para gáudio dos seus caçadores. Ao invés de ser testemunho da valentia e da virilidade do rei, esta fotografia, na perspetiva do cronista, mostra as falhas no seu ethos. 


\subsubsection{A revista Visão}

Na mesma linha de organização temática e estratégica, a crónica humorística publicada na revista Visão ridiculariza a figura do rei de Espanha pelo facto de ele ter participado numa caçada a elefantes:

(3) Os elefantes que paguem a crise

Espanha está mergulhada numa das mais graves crises da sua história. Perante uma situação tão difícil, o rei fez o que qualquer grande estadista faria e tomou a única decisão possível: foi caçar elefantes para África. (Visão, 19/4/2012, pp. 106)

Nesse caso, o título é construído sobre um lugar-comum amplamente difundido no passado recente de crises políticas em Portugal, um slogan caraterístico da esquerda nacional, típico do período pós-revolucionário da instauração do regime democrático e ainda, por vezes, recuperado da memória coletiva: "os ricos que paguem a crise". Nesta recuperação interdiscursiva, absurda mas operativa na construção discursiva do artigo, a caçada aos elefantes surge como improvável solução. Tal como no caso do texto anteriormente analisado, verifica-se uma relação causal entre a caça aos elefantes e o mal-estar humano (já não o real tédio, mas a crise económica).

O parágrafo inicial do artigo opera uma contraexpectativa promotora de humor: traça o cenário de elevado grau de risco, começa por desenhar uma personagem à altura desse alto grau (descrevendo o rei como "grande estadista") e aponta o caráter singular da decisão, numa linha de desenvolvimento coerente. Mas ilustra a tomada de decisão com um ato inoperante para o fim anunciado, compatível com os implícitos produzidos no título: caçar elefantes. Naturalmente, a avaliação positiva em alto grau do indivíduo focalizado é invertida e transforma-se numa desqualificação intensa. O rei de Espanha é ridicularizado por, em circunstâncias tão graves, realizar um gesto frívolo, sendo os dois ligados por uma relação causal - naturalmente, 
produzida intencionalmente pelo discurso do enunciador, fruto da sua modalização dos estados de coisas.

Um segundo segmento da mesma crónica é igualmente digno de análise atenta:

(4) A caça ao elefante tem tudo para ser um desporto emocionante. A dúvida constante de saber se o praticante terá pontaria suficiente para conseguir acertar num bicho que, além de ter uma excecional capacidade de se camuflar, ainda é extremamente irrequieto, deve ser de cortar a respiração. Mas o rei, habituado a não conseguir obter nada facilmente, aprecia desafios trabalhosos. (Visão, 19/4/2012, pp. 106)

Nesse segmento, a ironia não é linguisticamente marcada por algum tipo de indicador formal, mas o seu reconhecimento resultará da flagrante divergência entre a descrição dos estados de coisas que o texto opera e a enciclopédia do leitor. A este caberá reconhecer que o enunciador se distancia do enunciado porque, um quadro de normalidade, as suas afirmações são incompatíveis com o conhecimento do mundo supostamente partilhado por ambos. O locutor, apesar de não introduzir no enunciado qualquer marca formal que assinale a divergência enunciativa, não deixa de marcar a sua modalização com avaliações de alto grau, que clarificam a sua intenção: "excecional capacidade de se camuflar", "extremamente irrequieto".

Fruto do processo de distanciamento enunciativo e da correspondente inversão de polaridade, a caçada ao elefante surge, assim, na modalização efetuada, como uma atividade muito pouco atrativa ou emocionante, de fim previsível e altamente injusto, e isenta de mérito, tudo o que contraria a ideia de competição desportiva, seja de que tipo for, pois esta envolve tipicamente a igualdade de condições entre os competidores, a incerteza quanto à vitória e o mérito do vencedor.

A inversão de polaridade reconhecida pelo leitor no conteúdo da primeira frase do segmento recortado adquire potencialidade de se 
prolongar para a segunda frase do mesmo segmento. Assim, os estados de coisas descritos, formalmente positivos para a imagem do rei, invertem o seu sentido, transformando-se em críticas agudas que, mais uma vez, afetam a personalidade de Juan Carlos: este estaria habituado a tudo obter de modo fácil e, portanto, não teria a capacidade para defrontar desafios exigentes, limitando-se a competições com vitória garantida - não por mérito próprio, mas por ação alheia ou condições injustas.

\subsubsection{O Diário de Notícias (DN)}

Um terceiro texto de enunciação subjetivizada deve ser individualizado. Trata-se de um artigo de opinião, publicado no DN em 19/4/2012 e intitulado "frivolidade e austeridade", título construído, mais uma vez, sobre as incongruências publicamente denunciadas na atitude de Juan Carlos e sobre um processo interdiscursivo de recuperação das acusações feitas ao rei e difundidas nos jornais espanhóis: as acusações de "frivolidade" e de "falta de ética" foram feitas, segundo o DN de 15/4 (pp. 24) pela esquerda Unida e pelo Partido Nacionalista Basco.

Este artigo compara a atitude de Juan Carlos à de um milionário português já falecido, antigo caçador que, em determinada altura, terá abandonado essa atividade, tendo declarado que "começara a sentir uma espécie de náusea quando compreendeu que a caça estava a contribuir para o desaparecimento de muitas espécies" (DN, 19/4/2012, pp. 9). O enunciador considera que, com essa atitude, o antigo caçador:

(5) limitou-se a ser consequente nos atos com aquilo que lhe parecia ser um imperativo ético evidente. É essa a diferença que separa a profundidade da frivolidade. O Rei de Espanha enverga na lapela o emblema da organização conservacionista WWF, mas continua a matar elefantes, uma das espécies mais emblemáticas e ameaçadas do mundo. (DN, 19/4/2012, pp. 9) 
A comparação é altamente penalizadora para Juan Carlos. Se acusações a um rei podem ser graves, esta de ser frívolo, incoerente, superficial, é consideravelmente séria. Note-se que ultrapassa o erro momentâneo, aquilo que é marcado por aspeto pontual, para atingir o que é durativo, constante, constitutivo do ser, para o ethos do monarca espanhol, aquilo que é a sua última reserva de dignidade. A comparação é igualmente penalizadora porque o elemento de comparação é um outro caçador que compreendeu o seu erro (na perspetiva do enunciador). Não se trata de um ambientalista $a b$ initio, de um jovem ativista radical, de um extremista republicano, mas de um velho milionário insuspeito de professar ideais de esquerda. Mesmo esse, mesmo alguém que partilharia, genericamente, dos ideais de vida do monarca, teria reconhecido o erro de caçar elefantes. E é significativa a afirmação segundo a qual ele teria sentido "uma espécie de náusea", na medida em que tal reação proviria do íntimo involuntário de si, do seu ser profundo, não se tratando em primeira instância de uma decisão consciente da vontade - essa teria, posteriormente, resultado do imperativo vital. $\mathrm{O}$ rei de Espanha não teria essa capacidade de sentir náusea por matar elefantes, porque, no seu íntimo, se sentiria bem com esse facto: um é profundo, o outro frívolo.

Trata-se, assim, de um verdadeiro discurso polémico, que efetua um violento ataque ao fulcro do seu alvo.

\subsection{Algumas considerações preliminares}

As considerações desenvolvidas, em particular em torno dos três textos objeto de atenção mais detalhada, permitem observar que a personagem principal desta narrativa é fortemente desqualificada, nomeadamente com base em critérios e discursos de fundo ambiental, mas o argumento ambiental não é, em si, discutido. É assumido como incontestável que matar elefantes é mau e que quem o faz sofre de uma falha ética grave, mas os textos não questionam essa base argumentativa.

Aparentemente, a sociedade portuguesa terá ultrapassado já a fase de alerta e discussão sobre esta temática, para se encontrar 
numa outra fase, a de conciliar os atos individuais e coletivos de puro usufruto do meio e dos seus recursos àquilo que a razão e a nova ética social exigem. Contudo, é possível identificar textos que ainda questionam a base argumentativa pró-ambiental.

Um desses textos é um artigo de opinião publicado no semanário Expresso, em 21/4/2012. Além de evocar os ativistas ambientais, em geral, como "lóbis barulhentos", promovendo a sua desqualificação e a do seu discurso, desvaloriza a polémica que envolveu a caçada real, que atribui exclusivamente aos defensores do ambiente:

(6) Eu compreendo que não é tempo de grandes festas nem de férias ostentatórias. Mas se o rei, em vez de uma caçada, tivesse ido tirar fotografias ao deserto do Kalahari (gastando exatamente o mesmo pecúlio), alguém se escandalizaria com o fausto real? Não! O farisaísmo tartufo surge porque houve caçada!

Aos altifalantes da berra nem lhes importa ponderar os muitos estudos que indicam ficarem as espécies mais bem protegidas pela existência de coutadas de caça. (...)

Os muitos cronistas que andaram a disparar sobre Juan Carlos fazem parte de um grupo terrível: aqueles que gostam de impor aos outros os seus preconceitos pessoais. (Expresso, 21/4/2012, pp. 40)

Nesse segmento, o enunciador assume uma modalização dos estados de coisas bem diversa da que é assumida pela maioria dos autores dos restantes textos do corpus, acusa os ativistas ambientais de serem falsos, evoca estudos que mostrarão, do seu ponto de vista, que a caça protege as espécies e aponta uma das características reconhecidas ao ambientalismo: o seu caráter diretivo, a sua pretensão de mudança das mentalidades e dos atos dos cidadãos e dos grupos ${ }^{11}$.

Contudo, a ligação entre ética e ambientalismo está também nesse caso evidenciada. Ao apelidar os ativistas ambientais de tartufos,

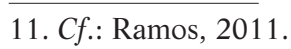


o enunciador está a negar-lhes o reconhecimento da ética sobre a qual frequentemente o discurso ambiental se constrói - o que significa, por outro lado, que reconhece que é esse um dos argumentos ambientais de uso frequente. E, para este articulista, as críticas a Juan Carlos que evocam o quadro económico não seriam mais do que críticas de teor ambiental camufladas. Verifica-se, nesse artigo, uma recusa dos argumentos de base sobre os quais a maioria dos restantes textos labora, o que encerra o potencial de relançar a discussão em torno da questão.

\section{Considerações finais}

A observação atenta dos textos que constituem o corpus deste estudo mostra que há uma transferência ou cruzamento de campos discursivos - o político, o popular, o económico e o ambiental intersecionam-se. Além disso, os textos dos jornais (não só os de enunciação subjetivizada, mas também os de enunciação objetivizada) são construídos como discursos terceiros, sobre um discurso primeiro, o que deu conta do facto bruto, e um discurso segundo, as reações públicas ao tratamento mediático desse facto, manifestadas como parte integrante do evento mediático ${ }^{12}$. As acusações de "frivolidade" e de "falta de ética" foram feitas pelas forças sociais e políticas espanholas e são retomadas por líderes de opinião portugueses.

É notória a existência de um ataque ao caráter do rei-aquilo que é focalizado como evento, ocorrência momentânea, ganha dimensão de estado, caraterística permanente, profunda e edificante do ser. Tratase de uma questão de ethos, e neste aspeto a narrativa da vida social

12. I. M. Duarte afirma que "é uma constante de qualquer discurso citar palavras de outros (ou do seu próprio locutor), de modo direto, indireto, ou de formas mais subtis e menos visíveis, como alusões, ecos irónicos, negação, reprodução de léxico alheio, pressuposições, etc." (2003: 185-186) e ainda que "a atividade discursiva é predominantemente citacional" (idem, ibidem: 186). No caso específico da imprensa, defende que o mesmo "se afirma sobre o discurso jornalístico dos nossos dias: assiste-se a uma generalização do discurso citado, em detrimento do discurso plenamente assumido pelo seu enunciador" (idem, ibidem: 186). 
(política, familiar, económica) funde-se com o discurso ambiental, frequentemente alicerçado sobre a ética. Os ambientalistas, de forma geral, apresentam-se como imbuídos de uma ética que os autoriza a realizar atos discursivos diretivos, fundamentando-se em razões onde o bem comum adquire papel de relvo e a ciência cruza os discursos para lhes oferecer vocabulário, estruturas e modos de organização textual, assim como para os credibilizar. Assim, o contraste intensifica-se entre os defensores da ética e o alvo denunciado de falta dela.

Não há, contudo, real espaço para discutir a base da desqualificação do rei. Parece estar interiorizado na opinião pública portuguesa e ser inquestionável que não se mata elefantes, seja por que motivo for; é assunto que nem se discute. Não sendo particularmente passível de polémica, também não é explorado pela maioria dos jornais, que preferem centrar-se no que é polémico: a questão económica, os casos mais ou menos escandalosos recentemente ocorridos no seio da família real, a infidelidade de Juan Carlos e as divergências políticas / de regime (monárquicos versus republicanos).

Ainda assim, surgem (poucas) vozes contestatárias, que incorporam o mérito de suscitar a reflexão sobre a relação homem / ambiente em torno deste caso particular, tornando consciente a assunção dos valores defendidos pelos ativistas ambientais ou permitindo a sua rejeição fundamentada. Em qualquer dos casos, a reflexão sobre o assunto parece ser positiva e a análise atenta dos discursos que constroem o ambientalismo pode ter um papel adjuvante e relevante nesse processo.

Recebido: 05/10/2012

Aceito: 20/11/2012

rlramos@ie.uminho.pt 


\section{Referências bibliográficas}

BENVENISTE, E. Problèmes de linguistique générale, 2. Paris: Gallimard, 1974.

BRONCKART, J.-P. Atividades de Linguagem, Textos e Discursos. Por um Interacionismo Sociodiscursivo. São Paulo: Educ, 2009.

CHARAUDEAU, P. Le discours d'information médiatique. La construction du miroir social. Paris: Nathan, 1997.

DRYZEK, J. S. The politics of the earth: environmental discourses. Oxford: Oxford University Press, 1997.

DUARTE, I. M. O relato de discurso na Crónica de D. João I (I Parte) de Fernão Lopes. In Lingua Portuguesa: estruturas, usos e contrastes, p. 185-98. Porto: Centro de Linguística da Universidade do Porto, 2003.

DUCROT, O. Le dire et le dit. Paris: Minuit, 1984.

FILLMORE. Ch. An alternative to checklist theories of meaning. In: Proceedings of the first annual meeting of the Berkeley Linguistic Society, p. 123-131. Berkeley, 1975.

FONSECA, J. Apresentação. In: J. FONSECA (org.), A. G. PINTO; C. ALMEIDA; R. RAMOS. A Organização e o Funcionamento dos Discursos, p.7-8. Estudos sobre o Português, Tomo III. Porto: Porto Editora, 1998.

HALLIDAY, M. A. K. New Ways of Meaning: The Challenge to Applied Linguistics. In: A. FILL e P. MÜHLHÄUSLER (orgs.) The ecolinguistics reader. Language, ecology and environment, p. 175-202.. London / New York: Continuum, 2001.

JUNG, M. Ecological Criticism of Language. In: A. FILLe P. MÜHLHÄUSLER (orgs.) The ecolinguistics reader. Language, ecology and environment, p. 27085. London / New York: Continuum, 2001.

KERBRAT-ORECCHIONI, C. La polémique et ses définitions. In: Le discours polémique, p. 3-40. Lyon: Centre de Recherches Linguistiques et Sémiologiques de Lyon, Presses Universitaires de Lyon, s/d.

MCKENZIE, P. Interpretative repertoires. In: K. FISHER; S. ERDELEZ; L. MCKECHNIE (orgs.) Theories of information behavior: A researcher's guide, p. 221-24. Medford, NJ: Information Today, 2005. 
MOIRAND, S. Les indices dialogiques de contextualization dans la presse Ordinaire. Cahiers de praxématique, 33: 145-84, 1999.

POTTER, J.; WETHERELL, M. Discourse and social psychology; beyond attitudes and behaviour. London: Sage, 1987.

RAMOS, R. Os doze abutres: estrutura e funcionamento de um texto polémico. In: J. FONSECA (org.), A. G. Pinto; C. Almeida; R. Ramos. A Organização e o Funcionamento dos Discursos. Estudos sobre o Português, p. 109-56. Tomo III. Porto: Porto Editora, 1998.

. Organização e funções do dossier de imprensa. O caso do discurso mediático do ambiente em Portugal. In: A. BONINI et al. (org.) Anais do SIGET - $4^{\circ}$ Simpósio Internacional de Gêneros Textuais, p. 1776-91. Tubarão: Universidade do Sul de Santa Catarina, 2007.

O discurso do ambiente na imprensa e na escola. Uma abordagem linguística. Lisboa: Fundação Calouste Gulbenkian / Fundação para a Ciência e a Tecnologia, 2009.

The Organization and Functions of the Press Dossier: The Case of Media Discourse on the Environment in Portugal. In: Ch. BAZERMAN; A. BONINI; D. FIGUEIREDO (orgs.) Genre in a Changing World, p. 223-242. Fort Collins, Colorado / West Lafayette, Indiana: The WAC Clearinghouse and Parlor Press, 2009a.

Contributos para a caraterização da retórica ambiental na imprensa generalista portuguesa. Revista Galega de Filoloxia, 12: 155-176, 2011.

SEARLE, J. La construction de la réalité sociale. Paris: Gallimard, 1998.

VILELA, M. A "cena" da "acção linguística" e a sua perspectivação por dizer e falar. Revista da Faculdade de Letras. Línguas e Literaturas, XI: 65-97, 1994. 


\section{Anexos - Corpus}

Quadro 1 - Diário Público (10 peças)

\begin{tabular}{|l|l|l|l|}
\hline data & Autor & Título & Página \\
\hline $16 / 4$ & - & Rei voltou à caça e oposição não gostou & 37 \\
\hline $17 / 4$ & - & $\begin{array}{l}\text { Caçada do rei em tempos de crise abre debate } \\
\text { sobre família real }\end{array}$ & 1 \\
\hline $17 / 4$ & Nuno Ribeiro & Juan Carlos. Polémicas de uma caçada & $22-23$ \\
\hline $17 / 4$ & - & Sobe e desce & 48 \\
\hline $18 / 4$ & Luís Afonso & Bartoon & 45 \\
\hline $19 / 4$ & $\begin{array}{l}\text { Ana Fonseca } \\
\text { Pereira }\end{array}$ & $\begin{array}{l}\text { Inédito mea culpa de Juan Carlos para travar } \\
\text { "maior crise" da monarquia }\end{array}$ & 23 \\
\hline $20 / 4$ & - & O imparável tormento da Espanha & 50 \\
\hline $22 / 4$ & Nuno Ribeiro & Quem os viu e quem os vê. Rei Juan Carlos & 3 \\
\hline
\end{tabular}

Encarte humorístico "Inimigo público", diário Público

\begin{tabular}{|l|l|l|l|}
\hline $20 / 4$ & JH & $\begin{array}{l}\text { Rei Juan Carlos vai passar a caçar seitans e tofus em } \\
\text { safaris para agradar à esquerda }\end{array}$ & 4 \\
\hline $20 / 4$ & - & $\begin{array}{l}\text { 'Troika' prepara-se para intervencionar a Espanha e } \\
\text { obrigar o rei Juan Carlos a caçar apenas linces ibéricos } \\
\text { no seu país }\end{array}$ & 4 \\
\hline
\end{tabular}

Quadro 2 - Diário Diário de Notícias (28 peças)

\begin{tabular}{|l|l|l|l|}
\hline data & Autor & Título & Página \\
\hline $15 / 4$ & $\begin{array}{l}\text { Susana } \\
\text { Salvador }\end{array}$ & $\begin{array}{l}\text { Juan Carlos faz quarta operação em dois } \\
\text { anos após acidente de caça }\end{array}$ & 24 \\
\hline $15 / 4$ & - & Os sustos médicos do monarca de 74 anos & 24 \\
\hline $16 / 4$ & - & Dar o exemplo & 6 \\
\hline $16 / 4$ & $\begin{array}{l}\text { Susana } \\
\text { Salvador }\end{array}$ & Juan Carlos convidado a abdicar & 24 \\
\hline $16 / 4$ & - & Rei recupera bem e já anda de muletas & 24 \\
\hline
\end{tabular}




\begin{tabular}{|c|c|c|c|}
\hline $16 / 4$ & - & $\begin{array}{l}\text { O caçador que é presidente honorário da } \\
\text { WWF }\end{array}$ & 24 \\
\hline $17 / 4$ & - & Bardot diz que Rei foi indigno & 27 \\
\hline $18 / 4$ & Albano Matos & Juan Carlos prepara resposta à polémica & 26 \\
\hline $18 / 4$ & - & $\begin{array}{l}\text { Monarquia espanhola. Pontos fracos. Pontos } \\
\text { fortes }\end{array}$ & 26 \\
\hline $19 / 4$ & - & Rei Juan Carlos pede perdão & 1 \\
\hline $19 / 4$ & - & As desculpas reais & 6 \\
\hline $19 / 4$ & $\begin{array}{l}\text { Viriato } \\
\text { Soromenho- } \\
\text { Marques }\end{array}$ & Frivolidade e austeridade & 9 \\
\hline $19 / 4$ & $\begin{array}{l}\text { Susana } \\
\text { Salvador }\end{array}$ & Rei pede desculpas para travar polémica & 23 \\
\hline $19 / 4$ & - & Mohamed Eyad Kayali & 23 \\
\hline $19 / 4$ & - & $\begin{array}{l}\text { Espanha de olhos postos na alegada amante } \\
\text { do rei }\end{array}$ & 23 \\
\hline $20 / 4$ & - & $\begin{array}{l}\text { Juan Carlos. O que vai mudar na monarquia } \\
\text { após as desculpas do rei }\end{array}$ & 1 \\
\hline $20 / 4$ & $\begin{array}{l}\text { Susana } \\
\text { Salvador }\end{array}$ & Quando os reis se arrependem & $28-29$ \\
\hline $20 / 4$ & - & $\begin{array}{l}\text { Tributo de Isabel II a Diana tardou mas } \\
\text { acalmou críticas }\end{array}$ & 29 \\
\hline $20 / 4$ & - & $\begin{array}{l}\text { As desculpas do rei sueco devido a escândalo } \\
\text { sexual }\end{array}$ & 29 \\
\hline $20 / 4$ & - & Outros casos & 29 \\
\hline $20 / 4$ & Hélder Robalo & $\begin{array}{l}\text { "WWW vai reunir-se com o Rei para analisar } \\
\text { esta polémica caçada" }\end{array}$ & 56 \\
\hline $21 / 4$ & Albano Matos & Casa Real vai escapar à lei da transparência & 28 \\
\hline $21 / 4$ & - & Corinne apanhada na passadeira vermelha & 28 \\
\hline $22 / 4$ & - & $\begin{array}{l}\text { Espanha. Caçada de Juan Carlos relança } \\
\text { debate sobre o que é ser um rei }\end{array}$ & 1 \\
\hline
\end{tabular}




\begin{tabular}{|l|l|l|l|}
\hline $22 / 4$ & Hélder Robalo & $\begin{array}{l}\text { Polémica relação entre caça e conservação } \\
\text { das espécies }\end{array}$ & 27 \\
\hline $22 / 4$ & $\begin{array}{l}\text { Fernanda } \\
\text { Câncio }\end{array}$ & O rei que quis ser rei & $28-29$ \\
\hline $22 / 4$ & - & 10 momentos & $28-29$ \\
\hline $22 / 4$ & Raquel Costa & $\begin{array}{l}\text { "Não me espantaria se os reis de Espanha se } \\
\text { separassem" }\end{array}$ & 56 \\
\hline
\end{tabular}

Quadro 3 - Diário Jornal de Notícias (7 peças)

\begin{tabular}{|l|l|l|l|}
\hline data & Autor & Título & Página \\
\hline $15 / 4$ & - & Rei fratura anca em safari no Botswana & 30 \\
\hline $16 / 4$ & $\begin{array}{l}\text { Manuel } \\
\text { António Pina }\end{array}$ & Como os reis se divertem & 48 \\
\hline $17 / 4$ & $\begin{array}{l}\text { Maria João } \\
\text { Morais }\end{array}$ & Cresce contestação ao rei Juan Carlos & 30 \\
\hline $19 / 4$ & $\begin{array}{l}\text { Maria João } \\
\text { Morais }\end{array}$ & Pedido de perdão de um rei envergonhado & 30 \\
\hline $22 / 4$ & $\begin{array}{l}\text { Maria João } \\
\text { Morais }\end{array}$ & Um reino desencantado & 25 \\
\hline $22 / 4$ & $\begin{array}{l}\text { Catarina Cruz } \\
\text { 22/4 }\end{array}$ & $\begin{array}{l}\text { "Rainha Sofia é a mulher mais sozinha de de } \\
\text { Espanha" }\end{array}$ & 25 \\
\hline
\end{tabular}

Quadro 4 - Diário Correio da Manhã (7 peças)

\begin{tabular}{|l|l|l|l|}
\hline data & Autor & Título & Página \\
\hline $15 / 4$ & Paulo Madeira & Operado após queda em caçada & 31 \\
\hline $17 / 4$ & & Caçada do rei dá polémica & 28 \\
\hline $19 / 4$ & - & Acima abaixo & 2 \\
\hline $19 / 4$ & Ricardo Ramos & Rei Juan Carlos pede desculpa & 31 \\
\hline $21 / 4$ & Francisco Pina & Mau exemplo do Rei de Espanha & 15 \\
\hline $21 / 4$ & Paulo Fonte & Queda fatídica & 2 \\
\hline $21 / 4$ & João Vaz & Princesa alemã põe rei em cheque & 30 \\
\hline
\end{tabular}


Cadernos de Linguagem e Sociedade, 14 (1), 2013

Quadro 5 - Semanário Expresso (3 peças)

\begin{tabular}{|l|l|l|l|}
\hline data & Autor & Título & Página \\
\hline $21 / 4$ & Angel Luis de la Calle & Real caça e tiros pela culatra & 30 \\
\hline $21 / 4$ & A. L. C. & A mulher de que se fala & 30 \\
\hline $21 / 4$ & Henrique Monteiro & Elefantes e galinhas & 40 \\
\hline
\end{tabular}

Quadro 6 - Revista semanária Visão (3 peças)

\begin{tabular}{|l|l|l|l|}
\hline data & Autor & Título & Página \\
\hline $19 / 4$ & F. L. & Mais \& menos & 20 \\
\hline $19 / 4$ & J. D. M. & A tempestade perfeita & 64 \\
\hline $19 / 4$ & $\begin{array}{l}\text { Ricardo Araújo } \\
\text { Pereira }\end{array}$ & Os elefantes que pague a crise & 106 \\
\hline
\end{tabular}

